\title{
Compromissos éticos e inquietações estéticas
}

\author{
Paulo Eduardo Carvalho
}

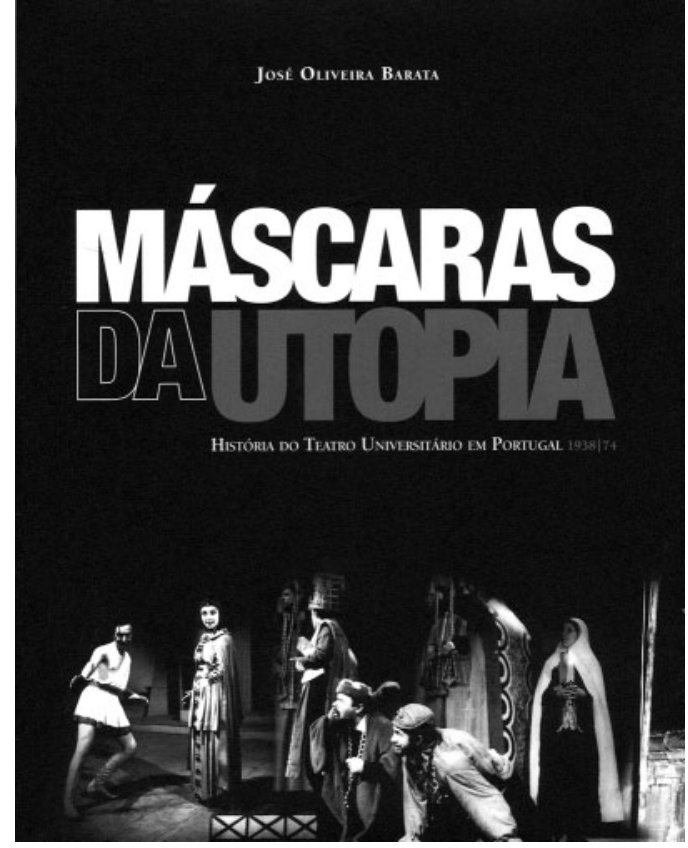

Comece-se pela evidência dos factos: quem, em Portugal, até há poucos meses, quisesse saber algo de mais desenvolvido e fundamentado sobre a contribuição dos agrupamentos universitários para a história do nosso teatro durante uma parte significativa do século XX, onde é que se poderia dirigir, que materiais é que poderia consultar? Claro que já poderia dispor de alguma informação através da consulta da CETbase

(http://www.fl.ul.pt/CETbase/default.htm), mas para uma apresentação mais sistematizada e crítica do muito que se fez e de como se fez teria de se limitar a materiais de muito difícil acesso, como por exemplo: o capítulo que Carlos Porto consagra ao teatro universitário no primeiro volume da sua valiosa recolha de textos críticos publicada em 1973, Em busca do teatro perdido, e as observações que o mesmo crítico dedica ao assunto tanto em "Entre la renovación y la dictatura", a sua contribuição sobre Portugal para Escenarios de dos mundos: Inventario teatral de Iberoamerica (1988), organizado por Moisés Perez Coterillo, como no capitulo "Outro teatro", do seu estudo O TEP e o teatro em Portugal: Histórias e imagens (1997). Qualquer uma das histórias do teatro português, como as de Luciana Stegagno Picchio, Luiz Francisco Rebello, o próprio José Oliveira Barata, António Tabucchi ou Duarte Ivo Cruz, só referem esta realidade de forma passageira.
José Oliveira Barata, Máscaras da utopia: História do teatro universitário em Portugal, 1938-74, Lisboa, Fundação Calouste Gulbenkian, 2009, 394 pp.

0 estudo mais recente de Graça dos Santos, 0 espectáculo desvirtuado: 0 teatro português sob o reinado de Salazar (1933-1968) (2004), tem a virtude de consagrar um capítulo ao teatro universitário. Acrescente-se, pela sua singularidade e interesse iconográfico, a iniciativa coordenada por Sílvia das Fadas, Vânia Álvares e Joana Maia, Esta danada caixa preta só a murro é que funciona: CITAC 50 anos (2006), que reúne diversos testemunhos de participantes activos na aventura daquele importante agrupamento coimbrão. Seja como for, além das já referidas dificuldades no acesso a alguma desta informação, haverá ainda que reconhecer, na maior parte dos casos, a sua condição lacunar, imprecisa e, sobretudo, descontextualizada.

A partir de Maio de 2009, qualquer leitor interessado passou a dispor do tratamento sistemático realizado por José Oliveira Barata, sob o título sugestivo de Máscaras da utopia e o subtitulo mais esclarecedor de História do teatro universitário em Portugal, 1938-74. São 394 páginas de riquíssima informação, tratada com rigor e amplo entendimento teórico e histórico, acompanhada por cerca de 275 reproduções de materiais vários (entre fotografias de espectáculos, programas, cartazes e outros documentos) e dois anexos (uma cronologia dos espectáculos e uma lista, "forçosamente incompleta", de participantes no teatro universitário). 0 livro integra ainda uma bibliografia que funciona como instrumento de pesquisas futuras, ao mesmo tempo que dá conta do extraordinário labor associado a este empreendimento: para além do próprio espólio pessoal do autor - que terá funcionado como uma "importante base de trabalho" - e da consulta de obras impressas, terá sido necessária uma intensa pesquisa em arquivos e bibliotecas - percorrendo relatórios de actividades, folhas informativas, textos teóricos para informação interna, comunicados, correspondência, críticas de jornais e revistas, os processos da censura prévia -, tudo isto completado com o recurso a fontes orais, incluindo entrevistas a 42 pessoas. Como o próprio autor esclarece, este é um objecto de ingrata fixação:

[A] vida dos vários de teatro universitário perde-se no amontoado de folhas policopiadas, programas dispersos, notas pessoais que esclarecem a (organizada) anarquia da produção dos espectáculos, 
nos amarelecidos rolos de cartazes que alguns ainda guardam como recordações, ou ainda num fundo iconográfico disperso e raramente datado. (36)

Máscaras da utopia apresenta uma estrutura irrepreensivel: depois de dois momentos introdutórios destinados a perspectivar teórica e historicamente o papel do teatro universitário, bem como a conjuntura propiciadora de novos interesses entre a comunidade académica, surge uma longa parte ocupada por capítulos dedicados ao tratamento individualizado dos diversos agrupamentos que fizeram a história do nosso teatro universitário: TEUC, TUP, CITAC, Cénico de Direito, o Grupo

Antigona, de Teatro da Faculdade de Letras, bem como outras

de Sófocles, "existências efémeras". Segue-se, depois, a consideração direcção artistica de Paulo Quintela, TEUC particularizada das publicações de alguns destes grupos, com destaque para os "boletins", as actividades culturais por eles promovidas e ainda os festivais e ciclos de teatro. Por último, destaca-se o nefasto constrangimento desempenhado pelos mecanismos censórios (incluindo uma lista das peças enviadas à censura pelos grupos de teatro universitário) e, em sentido contrário, o apoio decisivo assegurado pela Fundação Calouste Gulbenkian, "a instituição cultural que", como se diz logo no prefácio "mais fez pelo teatro universitário em Portugal" (11) - o que amplamente justifica que, em boa hora, esta mesma instituição tenha chamado a si a responsabilidade pela edição da obra.

Para lá da muita informação mais pormenorizada e

A sapateira prodigiosa de Federico Garcia Lorca,

direcção artistica

de Paulo Quintela, TEUC, 1963 (Paulo Quintel

e Margarida Lucas). da identificação de muitos dos agentes mais activos nestas aventuras, e entre os diversos aspectos absolutamente cativantes deste estudo, registe-se o modo como José Oliveira Barata atende com idêntica atenção, rigor $e_{i}$ acrescente-se, agudo sentido histórico e crítico, à dupla valência de compromisso político e de "inquietação estética" que acompanhou o trabalho de muitos dos grupos aqui estudados:

Ao contrário do teatro comercial que quase ignorava a importância e a qualidade estéticas, muitos dos que militaram no Teatro

Universitário viam essa participação na vida teatral como militância cultural, não descurando, antes exibindo como novidade no mundo teatral português, os seus compromissos estéticos, em ligação com rigorosas propostas éticas. (21)

0 autor ajuda-nos também a perceber a emergência da actividade pioneira do TEUC no quadro das movimentações europeias, com destaque para as experiências francesas, espanholas e alemãs, esclarecendo o modo como, afastando-se das iniciativas de "teatro escolar" e da "récita académica", o teatro universitário consegue então sair da universidade para inscrever a sua aç̧ão no contexto mais vasto da sociedade civil. Sempre atento às particularidades do sistema político português em que se inscreveram tais experiências, José Oliveira
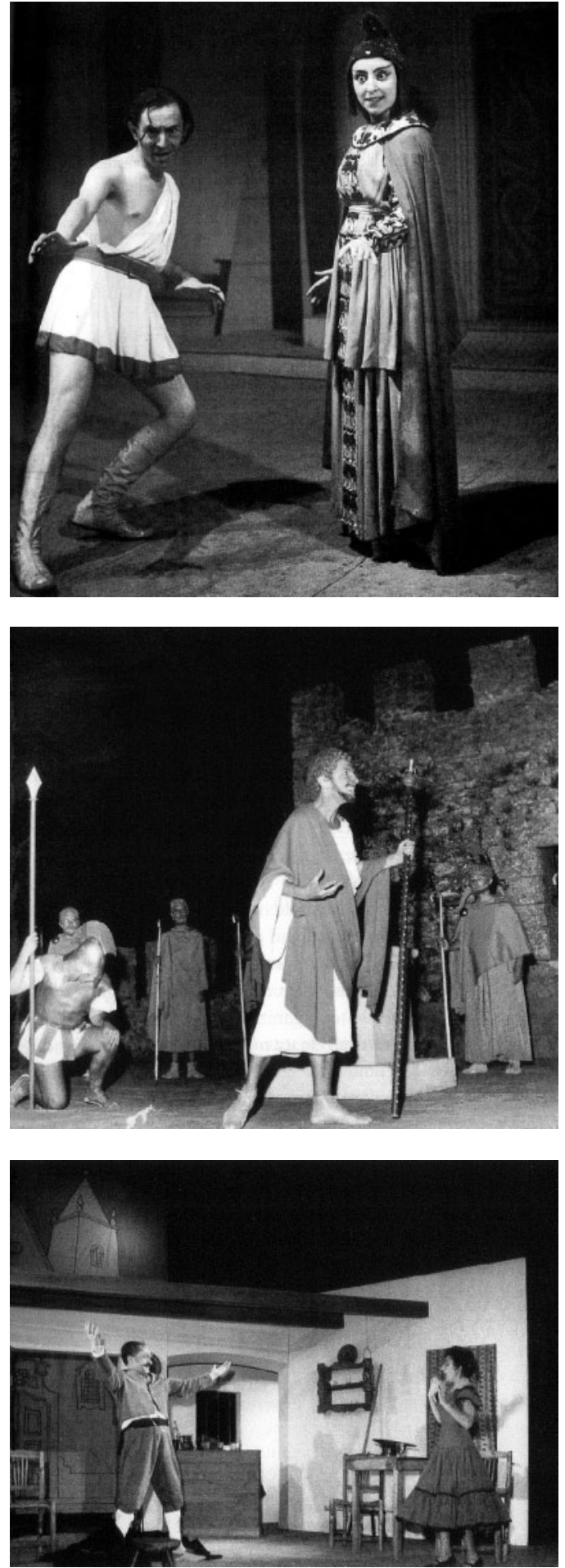

Barata ocupa-se, ainda antes de estudar a história do TEUC, das iniciativas dos "círculos universitários" sob a égide da Mocidade Portuguesa, em cujo âmbito o teatro era entendido como "instrumento de educação integral", e também do modo como a experiência do Teatro Universitário de Lisboa, ao qual chegou a estar ligada a figura de Fernando Amado, já nos anos cinquenta, se afasta do "tradicional caminho seguido pelos teatros subordinados aos ditames da Mocidade Portuguesa; desde logo pela recuperação de uma modernidade que, ficandose embora pelo rigor formal, colocava no palco novas alternativas estéticas, novos autores portugueses e 
estrangeiros" (67-68). Numa mesma linha de preocupação está, por exemplo, o tratamento das relações entre o TEUC e o regime do Estado Novo, isto é, as diversas tentativas que se foram sucedendo de "colar a actividade do grupo ao plano ideológico do regime" (99).

Compreensivelmente, de entre os muitos casos estudados, destaca-se a atenção concedida ao percurso do TEUC e, mais tarde, do CITAC, os agrupamentos de Coimbra. No primeiro dos casos, é com paciente pormenor que se explica e explicita a génese do grupo, a sua inscrição no ambiente académico coimbrão, as influências formadoras da direcção artística assegurada por Paulo Quintela e a própria novidade trazida pelo Teatro dos Estudantes da Universidade Coimbra: "novos intérpretes, repertório entusiasticamente vivido e interpretação despida dos vícios e convencionalismos adquiridos" (93), com destaque para o rigor na compreensão dos textos e uma nova forma de dizer que contrastava com a declaração tonitruante que ainda dominava a prestação de muitas das principais figuras do teatro português. 0 autor acompanha as fases sucessivas por que passou a vida do grupo, destacando contribuições menos reconhecidas como, entre outras, as de Manuel Deniz-Jacinto ou Arquimedes da Silva Santos, mas esclarecendo também o decisivo, embora complexo, papel nuclear de Paulo Quintela, determinante no movimento de redescoberta e divulgação da dramaturgia vicentina, dos clássicos portugueses e do legado trágico grego, capaz de um justo entendimento de que o texto dramático não se poderia esgotar no seu estudo enquanto texto literário, antes exigindo o desafio do palco, mas igualmente incapaz de se abrir a uma abordagem dramatúrgica e cénica menos dominada pela "sacralidade textual", e que, em alternativa, fosse mais ousada e imaginativa, como aquela que viria a ser praticada por Victor Garcia.

0 encenador argentino acabará, com justificada justiça, por emergir como o grande protagonista da actividade empreendida pelo CITAC:

0 sopro inovador de Victor Garcia fortalecera o grupo e soubera transmitir a todos os que com ele trabalhavam uma revolução nos tradicionais métodos de produção que se traduziam pela valorização do espaço cénico e da construção de um universo simbólico onde o texto e a maneira como era dito constituiam um sublinhado coral para tornar mais eficaz a poeticidade espectacular. (131)

Sempre atento ao quadro mais vasto do sistema teatral português em evolução, embora hesitante, é com singular pertinência que José Oliveira Barata destaca, nos primeiros anos de funcionamento do CITAC, a influência modelar do exemplo do TEP e de António Pedro ou o impacto mais tardio do Teatro Moderno de Lisboa. Depois de referir as contribuições de Luís de Lima, Jacinto Ramos e Carlos Avilez - cada um deles, a seu modo, responsável por importantes gestos de renovação, fosse a nivel do repertório ou dos procedimentos cénicos -, o autor demora-se no trabalho de Victor Garcia, cuja presença "marcaria de forma assinalável a vida do CITAC e determinaria um dos momentos mais altos da influência da experiência inovadora do Teatro Universitário no panorama do teatro português" (196).

Tal como José Oliveira Barata convincentemente esclarece, o CITAC tornou-se o intérprete privilegiado das teorias de Victor Garcia e da sua "genialidade demiúrgica" justamente por ter funcionado como uma espécie de "privilegiado laboratório onde testava a eficácia das suas arrojadas propostas cénicas" (203). As contribuições seguintes de Ricardo Salvat e, particularmente, de Juan Carlos Oviedo, não terão conseguido manter o mesmo nivel de riqueza artística.

Encontram-se ainda no livro valiosos estudos sobre outros importantes agrupamentos que não de Coimbra: o Teatro Universitário do Porto, outro exemplo de um grupo que, sob a inspiração inicial de Hernâni Monteiro, emerge devido ao entendimento do teatro universitário como "mais um elemento de uma pedagogia que devia sair da sala de aula e estender-se à comunidade" (149) e em cuja actividade se destacará a presença de Correia Alves que, vindo da tradição do TEUC, se abrirá aos ensinamentos de António Pedro, nomeadamente na renovação dos repertórios, com uma influente abertura ao teatro realista norte-americano; o Grupo Cénico da Associação de Estudantes da Faculdade de Direito da Universidade de Lisboa, apostado em "ser alternativa ao modelo de organização do teatro comercial" e em "propor um repertório que mostrasse às plateias portuguesas novas tendências da dramaturgia mundial" (220), no qual se registam as contribuições de Malaquias de Lemos, Fernando Midões, Fernando Gusmão, Luis de Lima e Adolfo Gutkin; a breve aventura do Teatro Académico da Universidade de Lisboa; e, finalmente, o Grupo de Teatro da Faculdade de Letras, caracterizado por um "mais evidente compromisso com a militância político-académica" (248), com um destaque natural para a produção já histórica de Anfitrião ou Júpiter e Alcmena, de António José da Silva, em 1969, dirigida pelo jovem, então com 19 anos, Luis Miguel Cintra - e que Maria Helena Serôdio já havia evocado no seu estudo sobre o percurso do encenador, Questionar apaixonadamente: 0 teatro na vida de Luís Miguel Cintra (2001).

Em "Existências efémeras", o autor ocupa-se do Grupo Cénico da Associação de Estudantes do Instituto Superior Técnico e do Grupo Cénico de Medicina, enquanto que reserva um revelador apontamento para a Oficina de Teatro dos Estudantes de Coimbra, uma experiência de "militância cultural de oposição ao movimento estudantil de esquerda", claramente marcado por um assumido pensamento da direita nacionalista, no entendimento de José Oliveira Barata. Tal como atrás já se adiantou, as considerações finais dedicam-se à importância dos boletins 


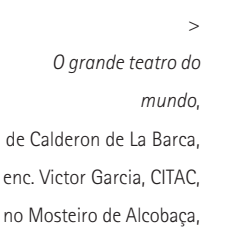

1968.

de Ben Jonson enc. Adolfo Gutkin, Cénico de Direito, Teatro Politeama, cultural do país, impondo-se pela coerência na escolha dos espectáculos" (305).

0 autor reserva ainda um merecido destaque à "lógica persecutória" da censura - o "estudo global e aprofundado do papel que as instituições censórias do Estado Novo desempenharam revelará como era complexa a teia opressora, nem sempre redutivel a decisões tomadas por cegueira, estupidez ou ignorância" (324) - e ao papel de "verdadeiro Ministério da Educação e da Cultura" desempenhado pela Fundação Calouste Gulbenkian:

No Portugal salazarista e caetanista, o apoio cultural da Fundação Calouste Gulbenkian foi uma constante. 0 papel desempenhado no reforço das estruturas logísticas e técnicas, através da atribuição de subsidios à produção de espectáculos, contratação de encenadores (portugueses e estrangeiros), deslocações a Festivais Internacionais, apoio a publicações pontuais ou a iniciativas de extensão cultural promovidas por grupos de teatro universitário, acabaria por alargarse às três universidades. (332)

Num estudo com esta amplitude e ambição, é natura que sobrevivam pequenas incoerências ou inconsistências de que é exemplo a que dá conta do facto de o CITAC, pela mão de Santos Simões, ter produzido Cavalgada para o mar, de J. M. Synge (e o nome do dramaturgo irlandês surge grafado de diferentes maneiras ao longo do texto) muito embora, mais adiante, este espectáculo não apareça referido na cronologia dos espectáculos, o primeiro dos anexos. Ou ainda, a propósito do mesmo texto, a ausência nessa mesma cronologia, de uma referência à produção pioneira do TUP, em 1956, sobre a qual se encontra informação avalizada em Teatro moderno: Caminhos e figuras, de Luiz Francisco Rebello, co-tradutor da peça, aparecendo esta produção remetida para o ano de 1961. (A propósito: a fotografia que surge reproduzida na página 155, com a legenda "Cena de 0 meu coração vive nas terras altas, encenação de Correia Alves", corresponde, na verdade, à última cena dessa produção do TUP, em 1956 de Cavalgada para mar, a acreditar na informação

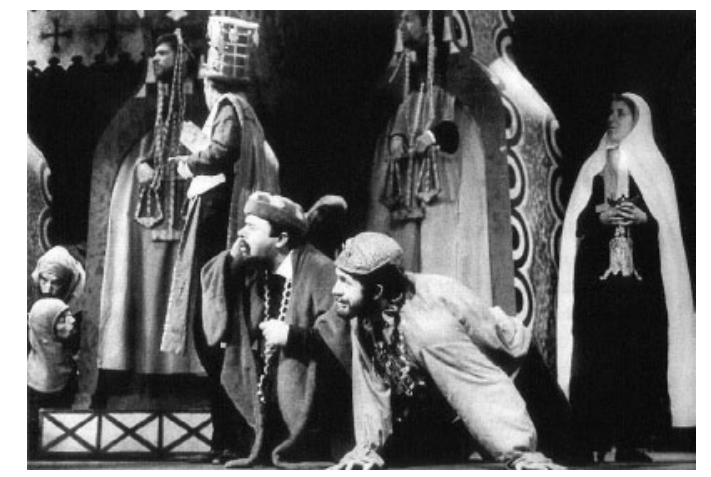

pessoalmente fornecida, mais uma vez, por Luiz Francisco Rebello.) Mas como, nas palavras do autor, a

"documentação reunida não foi tida como 'monumento' intocável e fixado de agora em diante como o repositório de toda a verdade" (23), entre um tal volume e uma tão grande complexidade de informação, muito ainda haverá certamente, a aperfeiçoar e a ajustar.

Mais lamentável é que os serviços editoriais da Fundação Calouste Gulbenkian não tenham sido mais cuidadosos na revisão do texto, desse modo evitando um número indesejável de erros tipográficos, e que não tenha sido possivel encontrar uma solução gráfica mais feliz, tanto a nivel da escolha do papel como da reprodução e inserção gráfica das muitas dezenas de fotografias que enriquecem este estudo. Igualmente questionável é a opção do autor em manter na língua original muitas das citações em línguas estrangeiras, opção que, embora ainda aceitável em trabalhos académicos, não se justifica em obras que se dirigem a um público mais alargado.

Naturalmente, nenhuma destas observações põe em causa ou diminui o valor deste trabalho literalmente extraordinário, que vem preencher uma das mais nossas gritantes lacunas historiográficas, desse modo contribuindo para um mais correcto e amplo conhecimento do teatro português do século XX. Na sua experimentada e fundada articulação de pesquisa, rigor histórico e espírito crítico, Máscaras da utopia é a demonstração modelar do que ainda há de entusiasmante para se fazer e para se conhecer. Espera-se ainda que este trabalho possa ser estímulo suficiente para prosseguir, para lá de 1974, o estudo sistemático do percurso subsequente de alguns dos agrupamentos cuja génese e primeira história são, nesta obra, tão eloquentemente traçadas. 